\title{
Performance Evaluation of Sugarcane Bagasse Ash-Based Cement for Durable Concrete
}

\author{
A. Bahurudeen and Manu Santhanam \\ Department of Civil Engineering, IIT
}

\begin{abstract}
Sugarcane bagasse ash (SCBA) is obtained as a by-product from cogeneration combustion boilers in sugar industries. Bagasse ash is mainly composed of reactive silica and can be used as pozzolanic material in concrete. Previous studies have reported that the utilization of SCBA as pozzolanic material in concrete can significantly improve its performance. A comprehensive investigation of durability performance of bagasse ash in concrete is not available in existing literature. In all previous studies, raw bagasse ash was ground to cement fineness and directly used in the concrete for the performance evaluation, without suitable characterization. Development of SCBA-based Portland pozzolana cement and its influence on the durability performance of concrete are discussed in this article. Durability performance was investigated by five different methods in this study. The methods used were rapid chloride penetration test (RCPT), chloride conductivity test, water sorptivity test, and Torrent air permeability test. The results from this study show that use of SCBA in concrete significantly enhances its durability performance.
\end{abstract}

Keywords: durability, mineral admixtures, permeability, Portland pozzolana cement, pozzolanic activity, sugarcane bagasse ash.

\section{INTRODUCTION}

Sugarcane bagasse ash (SCBA) is obtained in abundant quantities from sugar industries. After crushing of sugarcane in sugar mills and extraction of juice from processed cane by milling, the discarded fibrous matter is called bagasse. Bagasse is used as fuel in the cogeneration boiler to generate steam for the production of sugar as well as electricity. Bagasse is burnt at around $500^{\circ} \mathrm{C}$ in a controlled process to use its maximum fuel value. The residue after burning, namely, bagasse ash, is collected using a bag-house filter. Bagasse ash is directly disposed to the nearest land as slurry.

Plants ingest orthosilicic acid from ground water (Kamiya, Oka, Nasu, \& Hashimoto, 2000). When bagasse is burnt in the boiler of cogeneration plant under controlled conditions, reactive amorphous silica is formed due to the combustion process and is present in the residual ashes (Nuntachai, Chai, \& Kraiwood, 2009). This amorphous silica content makes bagasse ash a useful cement replacement material in concrete (Ganesan, Rajagopal, \& Thangavel, 2007; Moises, Ernesto, \& Holmer, 2011).

Use of supplementary cementitious materials significantly enhances the microstructure of concrete and helps to attain less permeable concrete. Pore structure, pore connectivity, and interfacial transition zone (ITZ) of concrete influence to a great extent the mechanical and durability properties of concrete (Alexander, Ballim, \& Stanish, 2008). When pozzolanic materials are used, reactive silica present in these materials react with calcium hydroxide and produce additional C-S-H gel. Permeability of concrete is considerably reduced because of pore refinement as well as additional $\mathrm{C}-\mathrm{S}-\mathrm{H}$ formation.

A number of research studies have investigated the influence of fly ash, slag, metakaolin, rice husk ash, and silica fume on the durability performance of concrete. Resistance of concrete containing mineral admixtures against chloride and other deteriorating agents is significantly enhanced when compared with control concrete (Githachuri \& Alexander, 2013; Otieno, Beushausen, \& Alexander, 2014). Duan, Shui, Chen, and Shen (2013) studied the effect of slag and metakaolin on the microstructure, compressive strength, carbonation, freeze-thaw resistance, and permeability of concrete. Considerable reduction in permeability and improvement in ITZ were observed when compared with control concrete. Performance of volcanic tuff blended cements with high replacement levels in alkali-silica reaction and sulfate resistance was investigated by Turanli, Uzal, and Bektas (2005); reduction in expansion was observed when the blended cements were used. Shekarchi, Bonakdar, Bakhshi, Mirdamadi, and Mobasher (2010) investigated permeability of $15 \%$ metakaolin blended concrete, and reduction in water penetration $(50 \%)$, gas permeability $(37 \%)$, water absorption (28\%), and ionic diffusion (47\%) were reported. Similar observations for metakaolin have 
been reported by several researchers (Badogiannis \& Tsivilis, 2009; Khatib \& Clay, 2003; Zhang \& Malhotra, 1995). Resistance against penetrability of deleterious chemicals was found to be enhanced for fly ash, slag, metakaolin, silica fume, and rice husk ash blended concrete in earlier research studies. It is clear that use of different mineral admixtures improves the durability of concrete.

A detailed investigation of durability performance of bagasse ash is not available in the previous research studies. Chusilp et al. (2009) studied the performance of concrete containing bagasse ash against water permeability with different replacement levels, and reduction in the water penetration depth was reported. Instead of using a single test, there is a need to look at the durability performance of bagasse ash-based concrete by different test methods, because ingress of aggressive chemicals is based on different transport mechanisms, including permeation, adsorption, diffusion, migration, convection, absorption, sorption, and a combination of these above-mentioned mechanisms (Alexander et al., 2008). A systematic and thorough investigation of durability performance needs to be included in the performance evaluation for bagasse ash or any new pozzolanic material to enable its potential use in concrete. This paper describes durability performance of SCBA-based Portland pozzolana cement in concrete.

\section{EXPERIMENTAL PROGRAM}

Instead of direct addition of SCBA in concrete as supplementary cementitious material, SCBA-based Portland pozzolana cements were developed based on maximum pozzolanic performance to achieve desirable properties. Development of SCBA-based PPC and durability test methods are described in this section.

\subsection{Development of SCBA-based portland pozzolana cement}

For this study, the bagasse ash was collected in the wet condition from a disposal area. It was air-dried completely before characterization and use. The sample of raw bagasse ash consists of three different types of particles, namely, fine burnt particles, coarse fibrous unburnt (CFU) particles and fine fibrous unburnt (FFU) particles. Most of the particles of raw bagasse ash are completely burnt fine particles. The presence of fibrous unburnt particles (CFU and FFU) was visually observed in the raw bagasse ash. Incomplete burning of plant cellular structured fibers leads to presence of more amounts of fibrous particles in the raw bagasse ash. The structure and size of these fibrous particles are entirely different from the burnt fine particles. Proper characterization of individual particles in the raw bagasse ash was carried out to attain maximum proportion of reactive bagasse ash for the production of SCBA-based Portland pozzolana cement.

The structure of the bagasse ash particles was further investigated by scanning electron microscopy (SEM) in the secondary mode. Energy dispersive X-ray analysis was also used in conjunction with SEM to find the elemental composition of the detected phases. Irregular shape was observed in the microstructure of fine burnt particles at higher magnifications. These irregular particles were found to be rich in silica. FFU had a different cellular structure in the cell wall compared to CFU. Carbon was detected to be more than $80 \%$ in the elemental composition on

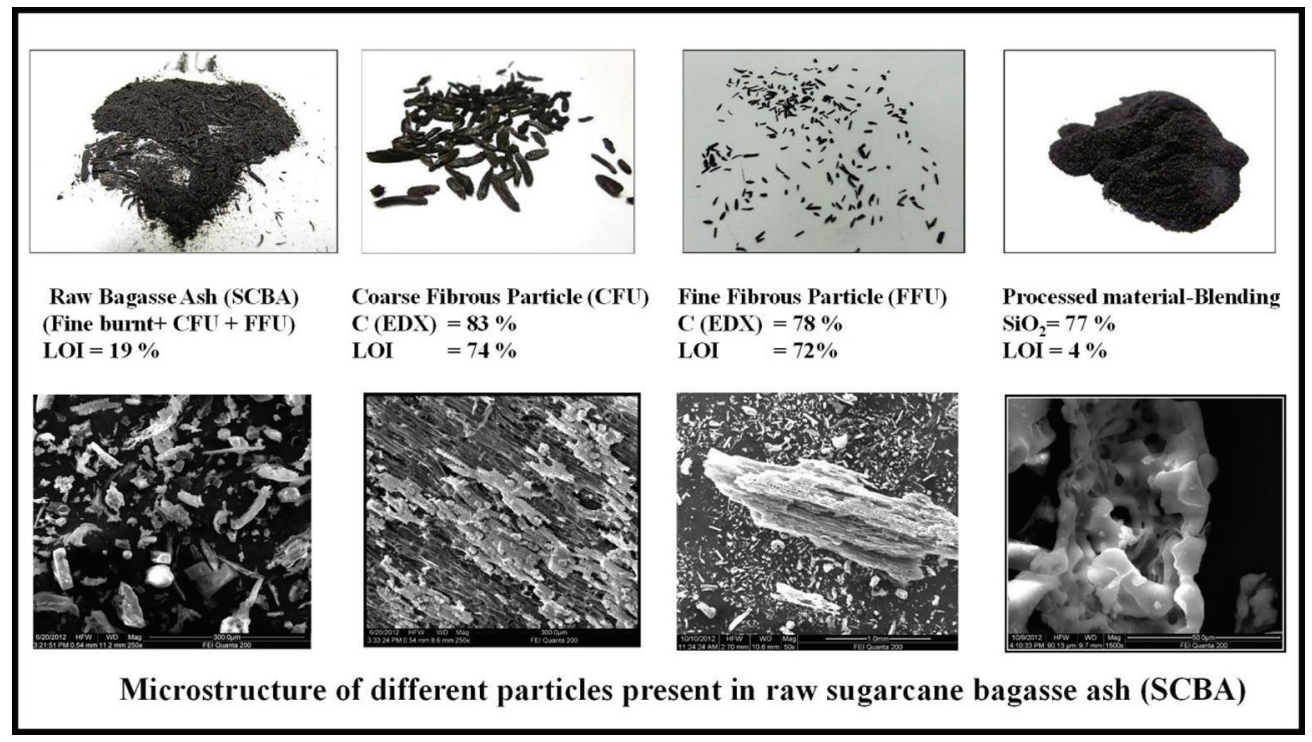

Figure 1. Different particles present in raw SCBA. 
the observed phases of fine fibrous particles. Typical carbon-rich cellular structure with scattered silica-rich epidermal layer was observed in the micrograph of coarse unburnt particles. Carbon was observed as the major element in the elemental composition (>78\%) in all the observed phases of the fibrous particles in the SEM micrograph and these results were further confirmed with loss on ignition test as per IS 17272004. Raw SCBA had higher loss on ignition (19\%) than permissible limit as per standard due to the presence of unburnt fibrous particles. From the above investigation, it is clear that fibrous particles consist of high carbon content and not reactive silica.

It is imperative to characterize pozzolanic performance of different particles in the raw bagasse ash to attain maximum reactive components for blended cement production. CFU and FFU were separated from raw bagasse ash. Pozzolanic performance of raw bagasse ash, coarse fibrous particles, fine burnt particles, and fine fibrous unburnt particles was investigated by five different pozzolanic evaluation methods (IS 1727-2004, ASTM 311-11b, EN 196-Part 5, Electrical conductivity method, and Lime saturation method) as a separate study by the same authors. Results from these tests showed higher pozzolanic activity for fine burnt particles and lesser pozzolanic index value for fibrous particles.

In this study, complete removal of CFU and FFU from raw bagasse ash was achieved by sieving. By several trials, it was found that sieving of dried raw bagasse ash through $300 \mu \mathrm{m}$ sieve leads to complete separation of silica-rich fine burnt particles from the fibrous particles. Sieved samples were further ground in a ball mill to cement fineness $\left(300 \mathrm{~m}^{2} / \mathrm{kg}\right)$. Complete removal of fibrous particles in the sieved material results in the reduction of loss on ignition to $<4 \%$. Pozzolanic activity index of sieved sample was $79 \%$ at 28 days, which is well above the minimum requirement mentioned in the standard. Pozzolanic activity of sieved and ground (SG) bagasse ash was found to be increased from 79 to $108 \%$, which was higher than control specimens. Thus, the oven-dried raw bagasse ash was sieved through $300 \mu \mathrm{m}$ sieve to remove all fibrous particles. Sieved material was further ground to cement fineness $\left(300-320 \mathrm{~m}^{2} / \mathrm{kg}\right.$ ) and used for blended cement with three different replacement levels $-10,15$, and $20 \%$. Physical characteristics of processed bagasse ash and SCBAblended cements were determined as per IS 17272004 and results are presented in Table 1. Even though initial and final setting times were increased with SCBA replacement, the observed values are well below the permissible limits. Finenesses (as well as particle size distribution) of ordinary Portland cement (OPC) and blended cements were found to be similar due to controlled processing,
Table 1. Physical characteristics of SCBA-based PPC cements.

\begin{tabular}{|c|c|c|c|c|c|}
\hline Characteristics & OPC & SCBA & $\begin{array}{l}10 \% \\
\text { PPC }\end{array}$ & $\begin{array}{l}15 \% \\
\text { PPC }\end{array}$ & $\begin{array}{l}20 \% \\
\text { PPC }\end{array}$ \\
\hline Specific gravity & 3.16 & 2.12 & 3.02 & 2.97 & 2.86 \\
\hline Fineness $\left(\mathrm{m}^{2} / \mathrm{kg}\right)$ & 310 & 300 & 306 & 313 & 317 \\
\hline $\begin{array}{l}\text { Soundness, } \\
\text { expansion (mm) }\end{array}$ & 0.73 & 1.21 & 1.30 & 1.10 & 1.36 \\
\hline Consistency (\%) & 30 & 40 & 35 & 40 & 40 \\
\hline $\begin{array}{l}\text { Initial setting time } \\
\text { (min) }\end{array}$ & 125 & 190 & 135 & 180 & 190 \\
\hline $\begin{array}{l}\text { Final setting time } \\
\text { (min) }\end{array}$ & 165 & 285 & 205 & 280 & 285 \\
\hline
\end{tabular}

Table 2. Oxide composition of SCBA-based PPC cements.

\begin{tabular}{lrrrrr}
\hline $\begin{array}{l}\text { Oxide } \\
\text { composition }\end{array}$ & OPC & SCBA & $\begin{array}{r}\mathbf{1 0 \%} \\
\text { PPC }\end{array}$ & $\begin{array}{r}\mathbf{1 5 \%} \\
\text { PPC }\end{array}$ & $\begin{array}{r}\mathbf{2 0 \%} \\
\text { PPC }\end{array}$ \\
\hline $\mathrm{SiO}_{2}$ & 20.68 & 75.67 & 25.82 & 31.16 & 36.41 \\
$\mathrm{Al}_{2} \mathrm{O}_{3}$ & 4.12 & 1.52 & 5.52 & 5.44 & 5.42 \\
$\mathrm{Fe}_{2} \mathrm{O}_{3}$ & 5.44 & 2.29 & 4.10 & 4.08 & 4.07 \\
$\mathrm{CaO}$ & 60.36 & 6.62 & 55.84 & 52.46 & 49.04 \\
$\mathrm{MgO}$ & 0.83 & 1.87 & 0.95 & 0.98 & 1.01 \\
$\mathrm{~K}_{2} \mathrm{O}$ & 0.27 & 9.59 & 0.31 & 0.64 & 1.01 \\
$\mathrm{Na}_{2} \mathrm{O}$ & 0.23 & 0.12 & 0.20 & 0.20 & 0.20 \\
\hline
\end{tabular}

and thus, the role of fineness was eliminated in the performance evaluation. Oxide composition of blended cements was determined using X-ray fluorescence and results are given in Table 2 . As expected, silica content present in the blended cement increases with increase in SCBA replacement.

\subsection{Methods}

Accelerated test methods based on migration are generally used to find the resistance of concrete against ingress of chloride ions. Four concrete mixes, with binder content of $360 \mathrm{~kg} / \mathrm{m}^{3}$ and $\mathrm{w} / \mathrm{b}$ of 0.45 , were prepared for the durability performance evaluation. Control mix and 5, 10, and $20 \%$ replacement mixes were cast for durability testing. OPC-graded (OPC 53 grade conforming to IS 12269) river sand as fine aggregate, crushed granite (confirming to IS 3831970 ) as coarse aggregate, and polycarboxylic etherbased high-performance super plasticizer (confirming to ASTM C494 Type-F to achieve 85-100 mm slump without segregation) were used in concrete mixes. In this study, rapid chloride penetration test (RCPT) based on ASTM C1202-12 and chloride conductivity test (as per South African DI manual) were used to assess resistance against chloride ion penetration. For RCPT, three specimens of $100 \mathrm{~mm}$ diameter and $50 \mathrm{~mm}$ thickness were used. Total charge passed over the test period in response to an applied DC potential of $60 \mathrm{~V}$ was determined in RCPT. For chloride conductivity test, after 28 and 56 days curing, specimens were cored and conditioned as per guidelines. Four test specimens of $70 \pm 2 \mathrm{~mm}$ diameter with thickness of 
$30 \pm 2 \mathrm{~mm}$ were prepared. Specimens were saturated with $5.0 \mathrm{M}$ sodium chloride solution. The specimen was then placed in a conductivity cell and applied voltage across concrete specimen was attained to $10 \mathrm{~V}$ by changing DC power supply, and the corresponding current was noted.

In this study, oxygen permeability test and Torrent air permeability test were used to evaluate the effect of bagasse ash on the resistance to gas diffusion. In oxygen permeability test, pressure in the cell was adjusted to $100 \pm 5 \mathrm{kPa}$ and initial pressure was noted in each cell. Pressure drop was recorded at an interval of $30 \mathrm{~min}$ for $6 \mathrm{~h}$ from the commencement of the test. The oxygen permeability index (OPI) was calculated as negative log of the average of the coefficients of permeability of the three tested specimens. Torrent air permeability test is based on Swiss Standard SIA $162 / 1-2003$ and is used to measure air permeability of the cover concrete. Effective pressure in the inner chamber was gradually increased with respect to the quality of cover concrete and rise in the effective pressure was recorded at the end of the test. Coefficient of air-permeability $k T\left(\mathrm{~m}^{2}\right)$ was determined.

Resistance against water permeation was examined by DIN water permeability test. Three specimens were placed in the permeability cell. Constant water pressure $\left(0.5 \mathrm{~N} / \mathrm{mm}^{2}\right)$ was applied on the concrete surface (other than casting surface) for 3 days. Afterwards, pressure was released and the specimens were removed immediately from the permeability cell. Specimens were split down along the tested direction and the depth of penetration was measured. Depth of penetration is directly represented as quality of concrete.

\section{RESULTS AND DISCUSSION}

According to ASTM 1202-12, electrical conductance of control and SCBA replaced specimens was measured in Coulombs to assess their resistance against chloride ion penetration. Total charge passed during test period was 3060 Coulombs for control specimens at 28 days curing and a marginal reduction $(3.5 \%)$ was observed for 56 days cured specimens. With reference to ASTM 1202-12 classification, control specimens were categorized as having "moderate" resistance against chloride ion penetration. Replacement of cement with bagasse ash remarkably enhanced resistance of concrete as well as significant reduction in electrical conductance was measured $(65,73$, and $81 \%$ reduction as compared to control specimens for 10,15 , and $20 \%$ SCBA replaced specimens, respectively, at 28 days) as represented in Figure 2. Concrete with SCBA showed higher resistance than control specimens at 28 days as well as 56 days, and can be categorized under "very low" permeability classification as per guidelines. RCPT gives good evidence of enhancement in the durability performance of SCBA-based concrete as compared to control concrete.

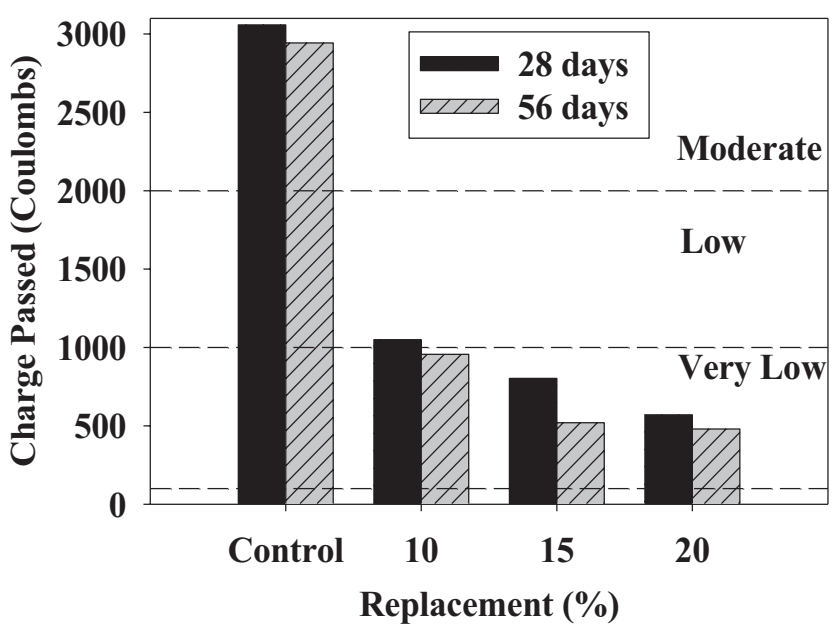

Figure 2. Total charge passed at 28 and 56 days curing.

Chloride conductivity index $(\mathrm{CCl})$ was measured after 28 and 56 days curing as per the method in South African DI manual and results are shown in Figure 3. $\mathrm{CCl}$ of control specimen was found to be more than SCBA-replaced specimens after 28 days as well as 56 days curing. When compared with control concrete, reductions in conductivity index were observed as 23,48 , and $54 \%$ for 10,15 , and $20 \%$ SCBA-replaced specimens, respectively, after 56 days curing. In terms of the qualitative classification suggested by Alexander, Mackechnie, and Ballim (1999), the concretes with 15 and 20\% SCBA attained an "excellent" condition after 56 days.

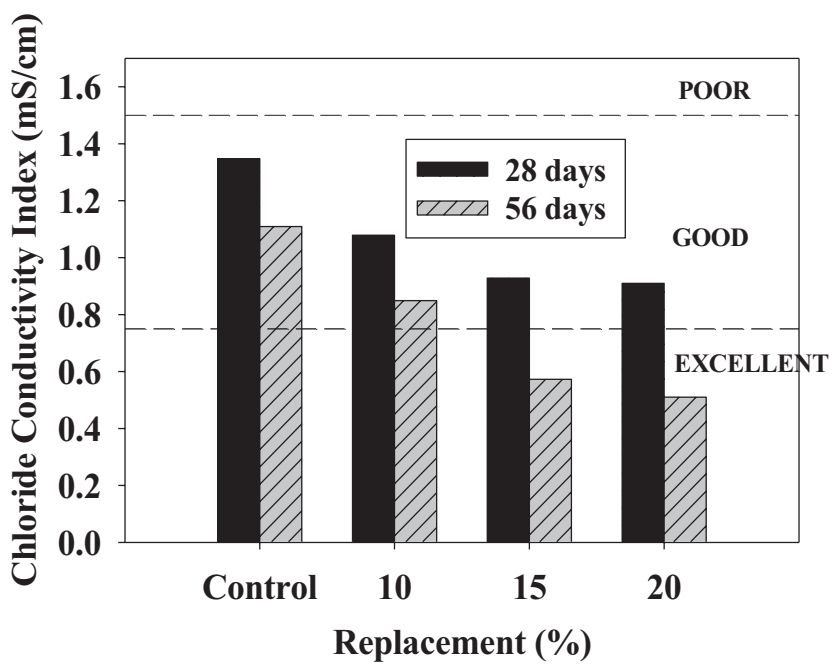

Figure 3. Chloride conductivity for concrete at 28 and 56 days curing.

From these observations, it can be concluded that resistance against chloride ion penetration was gradually increased to a greater extent with increase 
in the SCBA replacement. This can be attributed to the excellent pozzolanic performance of SCBA as well as improvement in the pore structure caused by pore refining.

Performance of control and SCBA-replaced specimens against gas permeability was investigated by oxygen permeability test and Torrent air permeability test. Oxygen permeability test provides a clear representation of the degree of pore connectivity in a concrete specimen whereas Torrent test helps to determine specifically the quality of cover concrete. Specimens were tested at 28 and 56 days and results are presented in Figures 4 and 5.

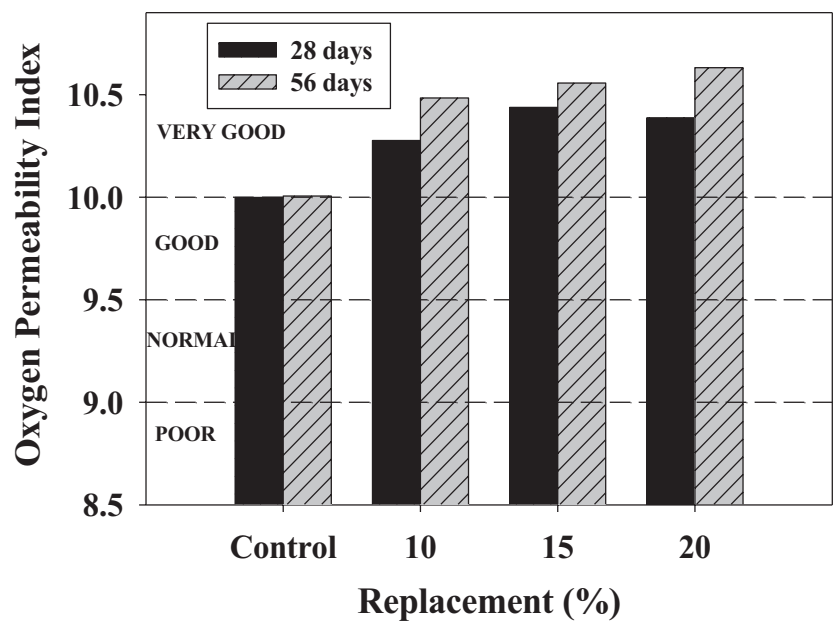

Figure 4. Oxygen permeability for concrete at 28 and 56 days curing.

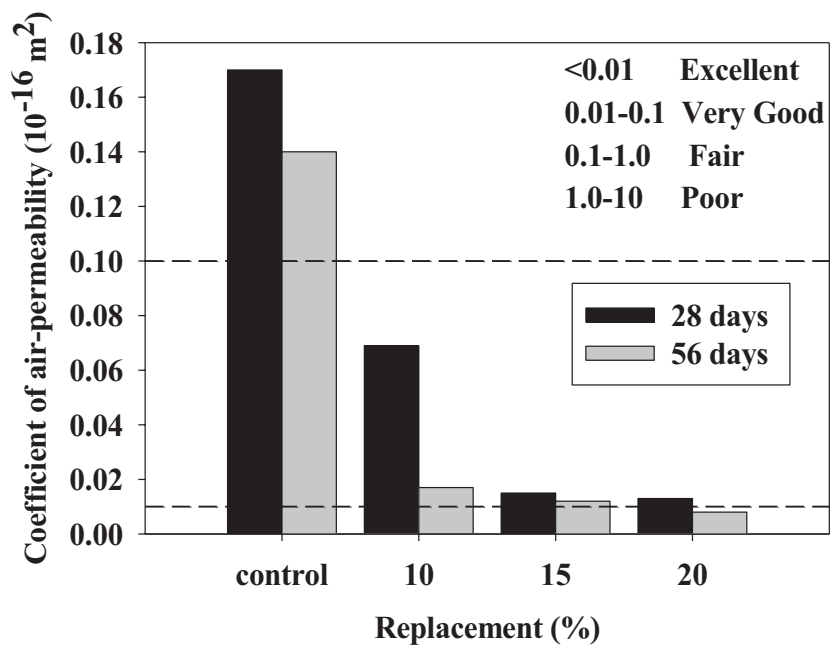

Figure 5. Torrent air permeability for concrete at 28 and 56 days curing.

OPI was found to be lower for control specimens when compared with SCBA replaced specimens at 28 days. Gradual increase in OPI with increase in SCBA replacement is a clear evidence for enhancement in pore structure. In addition to this, further reduction in OPI was observed at 56 days than 28 days cured specimens due to additional pozzolanic reaction. However, all the concretes can be categorized in the "very good" quality range as per the classification by Alexander et al. (2008).

In the Torrent test, based on the quality of cover concrete, increase or decrease in the effective pressure in the inner chamber was observed and equivalent coefficient of permeability $(k T)$ was determined. $k T$ for control specimens was found to be high $\left(0.17\right.$ and $\left.0.14 \times 10^{-16} \mathrm{~m}^{2}\right)$ for 28 and 56 days cured specimens, respectively, as shown in Figure 5. Substantial reduction in coefficient of permeability was measured for SCBA-replaced specimens. Even though similar $k T$ values were observed for 15 and $20 \%$ specimens, remarkable reductions were observed when compared with control specimens at 28 and 56 days curing because of improvement in the quality of cover concrete caused by better pozzolanic performance of SCBA. While the control concrete seems to be in the "fair" quality range, the concretes with SCBA seem to be in the border of "very good" and "excellent" ranges.

Resistance against water permeation was determined by water permeability test as per DIN-1048. Water penetration depth for control specimens was found to be high at 28 days $(8.1 \mathrm{~cm})$ and reduced to $6.5 \mathrm{~cm}$ at 56 days. Incorporation of SCBA in concrete noticeably influenced the resistance against water penetration. Average penetration depths for 10,15 , and $20 \%$ specimens were much lower at $7.0,5.8$, and $4.8 \mathrm{~cm}$, respectively. In addition to this, prominent reduction in water penetration depth was observed after 56 days curing for all SCBA-replaced specimens as compared to 28 days cured specimens as presented in Figure 6 . Significant reduction in the penetration depth is due to additional pozzolanic performance of SCBA.

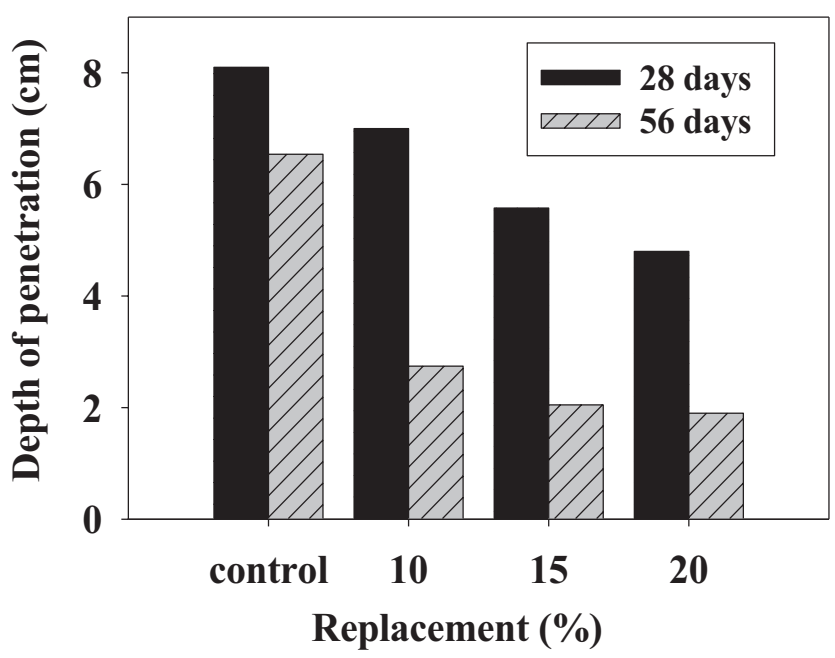

Figure 6. Water penetration depth for concrete at 28 and 56 days curing. 


\section{CONCLUSIONS}

- $\quad$ Raw bagasse ash has low pozzolanic activity and high loss on ignition due to the presence fibrous unburnt carbon particles. Removal of the fibrous carbon particles from raw bagasse ash, and further grinding to cement fineness was seen to significantly improve its pozzolanic activity.

- Durability performance of SCBA-based Portland pozzolana cements was investigated by five different methods. Blended cements were ground to similar fineness as OPC to completely exclude filler effect. Observed reduction in permeability with increase in SCBA replacements is purely from pozzolanic performance of SCBA.

- The oxygen permeability test showed only marginal increase in OPI for SCBA-blended cements. However, remarkable reduction in air permeability was observed for SCBA-replaced specimens than control concrete in Torrent air permeability test.

- $\quad$ Durability performance of SCBA-based Portland pozzolana cements against chloride permeability and water penetration were studied. Incorporation of SCBA in concrete substantially enhanced the resistance against water penetration and chloride permeability.

- Prominent reduction in permeability of concrete with increase in SCBA replacements is due to superior pozzolanic performance of SCBA as well as enhancement in the pore structure as a result of pore refinement.

- $\quad$ SCBAcan be used as supplementary cementitious material to achieve durable concrete.

\section{REFERENCES}

Alexander, M. G., Ballim, Y., \& Stanish, K. A. (2008). Framework for use of durability indexes in performance based design and specifications for reinforced concrete structures. Materials and Structures, 41, 921-36.

Alexander, M. G., Mackechnie, J. R., \& Ballim, Y. (1999). Guide to the use of durability indexes for achieving durability in concrete structures. Industry/FRD collaborative research programme: Achieving durable and economic concrete construction in the South African context. Research Monograph, 2, 5-11.

ASTM C1202. (2012). Standard test method for electrical indication of concrete's ability to resist chloride ion penetration. West Conshohocken, PA: Annual book of ASTM Standards.

ASTM C311-11b. (2011). Standard test methods for sampling and testing Fly Ash or Natural pozzolans for use in Portland-cement concrete. West Conshohocken, PA: Annual book of ASTM Standards.

Badogiannis, E., \& Tsivilis, S. (2009). Exploitation of poor Greek kaolins: Durability of metakaolin concrete. Cement and Concrete Composites, 31, 128-133.

BSI. (2005). Method of testing cement. Pozzolanicity test for pozzolanic cement. BS EN 196 Part 5.

DIN, (1994). Testing of hardened concrete. German Standards. DIN 1048 Part 5.

Donatello, S., Tyrer, M., \& Cheeseman, C. R. (2010). Comparison of test methods to assess pozzolanic activity. Cement and Concrete Composites, 32, 121-127.

Duan, P., Shui, Z., Chen, W., \& Shen, C. (2013). Enhancing microstructure and durability of concrete from ground granulated blast furnace slag and metakaolin as cement replacement materials. Journal of Materials Research and Technology, 2(1), 52-59.

Durability Index Testing Procedure Manual, (2009).

Ganesan, K., Rajagopal, K., \& Thangavel, M. (2007). Evaluation of bagasse ash as supplementary cementitious material. Cement and Concrete Composites, 29, 515-524.

Githachuri, K., \& Alexander, M. G. (2013). Durability performance potential and strength of blended Portland limestone cement concrete. Cement and Concrete Composites, 39, 115-121.

IS 1727. (2004). Methods of test for pozzolanic materials. New Delhi, India: Bureau of Indian Standards.

Kamiya, K., Oka, A., Nasu, H., \& Hashimoto, T. (2000). Comparative study of structure of silica gels from different sources. Journal of Sol-Gel Science and Technology, 19, 495-499.

Khatib, J. M., \& Clay, R. M. (2003). Absorption characteristics of metakaolin concrete. Cement and Concrete Research, 34, 19-29.

McCarter, W. J., \& Tran, D. (1996). Monitoring pozzolanic activity by direct activation with calcium hydroxide. Construction and Building Materials, 10, 179-84.

Moises, F., Ernesto, V., \& Holmer, S. (2011). Brazilian sugar cane bagasse ashes from the cogeneration industry as active pozzolans for cement manufacture. Cement and Concrete Composites, 33, 490-496.

Nuntachai, C., Chai, J., \& Kraiwood, K. (2009). Utilization of bagasse ash as a pozzolanic material in concrete. Construction and Building Materials, 23, 3352-3358.

Otieno, M., Beushausen, H., \& Alexander, M. G. (2014). Effect of chemical composition of slag on chloride penetration resistance of concrete. Cement and Concrete Composites, 46, 56-64. 
Shekarchi, M., Bonakdar, A., Bakhshi, M., Mirdamadi, A., \& Mobasher, B. (2010). Transport properties in metakaolin blended concrete. Construction and Building Materials, 24, 2217-2223.

SIA. (2003). Non-destructive site air-permeability test. Concrete construction complementary specifications. Swiss Standard Method. SIA 162/1-E.
Turanli, L., Uzal, B., \& Bektas, F. (2005). Effect of large amounts of natural pozzolan addition on properties of blended cements. Cement and Concrete Research, 35, 1106-1111.

Zhang, M. H., \& Malhotra, V. M. (1995). Characteristics of a thermally activated aluminosilicate pozzolanic material and its use in concrete. Cement and Concrete Research, 25, 1713-1725. 